The sensitivity of South African inflation expectations to surprises

MONIQUE REID

Stellenbosch Economic Working Papers: 16/09

KEYWORDS: SOUTH AFRICA, INFLATION TARGETING, MACROECONOMIC SURPRISES, SENSITIVITY OF INFLATION EXPECTATIONS.

JEL: E31, E52, E58

MONIQUE REID

DEPARTMENT OF ECONOMICS

UNIVERSITY OF STELLENBOSCH

PRIVATE BAG X1, 7602

MATIELAND, SOUTH AFRICA

E-MAIL: MREID@SUN.AC.ZA 


\title{
The sensitivity of South African inflation expectations to
}

\author{
surprises
}

MONIQUE REID*

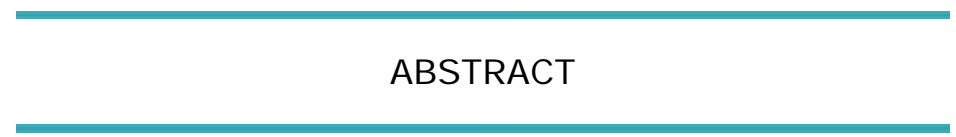

Price stability is widely recognised as the primary goal of modern monetary policy, and the management of private sector inflation expectations has become an essential channel through which this goal is achieved. This evaluation aims to improve the understanding of how the sensitivity of private sector inflation expectations to macroeconomic surprises in South Africa compares internationally, as this provides an indication of the contribution of monetary policy in South Africa to anchoring inflation expectations. If a central bank is credible, the financial markets should react less sensitively to macroeconomics surprises, because they trust the central bank to manage these incidents and achieve the objectives they communicated over the medium to long term. In this paper, the methodology of Gurkaynack, Sack and Swanson (2005a) is adopted in order to measure the sensitivity of South African inflation expectations to surprises. A comparison of South Africa's results with those of countries in the original studies supports the contention that the SARB (South African Reserve Bank) has encouraged inflation expectations to be relatively insensitive to macroeconomic surprises, and offers support for the inflation targeting framework as a means to help anchor inflation expectations.

Keywords: South Africa, Inflation targeting, Macroeconomic surprises, Sensitivity of inflation expectations.

JEL codes: E31, E52, E58.

Note: This paper is also available as ERSA Working Paper 131.

\footnotetext{
${ }^{*}$ The author acknowledges financial support for this project from ERSA. The author also wishes to thank Prof Stan Du Plessis for the supervision of her Master's thesis, from which this paper emanates, as well as the following people for invaluable assistance and advice: Theuns de Wet (RMB), Kevin Kotze (University of Stellenbosch) and George van der Westhuizen (Skerritt), Brett Lorge (Reuters), Liezelle Kotze (Reuters), Nasreen Seria (Bloomberg), Adri Cronjé (SARB) and Marietjie Bennett (Stats SA).
} 


\section{INTRODUCTION}

The maintenance of price stability is widely recognised as the primary goal of modern monetary policy, and the management of private sector inflation expectations has become an essential channel through which this goal is achieved. The inflation targeting framework for monetary policy adopted by the SARB is a forward-looking regime. At its core, it claims to anchor private sector inflation expectations, facilitating the achievement of price stability while limiting the output sacrifice (South African Reserve Bank, 2002). This central claim is evaluated in this paper and it is found that the SARB's success at anchoring inflation expectations in the face of macroeconomic surprises compares well with other leading inflation targeters.

Section 2 provides a theoretical exploration of modern monetary policy and section 3 reviews the available evidence regarding the transparency and credibility of South African monetary policy. The methodology of Gürkaynack, Sack and Swanson (2005a) is adopted in section 4 in order to measure the sensitivity of South Africa's inflation expectations to 'surprises'. A comparison of the South African results with those of countries in the original studies supports the contention that the SARB has anchored inflation expectations relatively well and that inflation targeting offers a useful framework for the management of private sector expectations.

\section{MODERN MONETARY POLICY}

It seems appropriate to base any critical evaluation of monetary policy operation in South Africa, or proposal for its improvement, on a sound understanding of the objectives and challenges facing contemporary monetary policy. Price stability has become widely accepted as the primary goal of monetary policy ${ }^{1}$. Monetarists emphasise the long-term effects of monetary policy in the pursuit of price stability, with Friedman (1968) calling attention to the lags between the implementation of monetary policy and its effects in the real world. This focus on the long term naturally drew attention to the role of expectations and required that purposeful monetary policy be forward-looking.

If it is recognised that economic policy is not a once-off, static decision, there needs to be a conscious awareness of the implications of applying policy in a dynamic setting. Optimal control theory has been widely used for dynamic problems, including policy decisions. If the private sector is a passive participant, the benevolent policy maker could maximise a social outcome by making an optimal decision, based on the state of the economy at the time and the historical development of policy up to that point.

\footnotetext{
1 This approach acknowledges that monetary policy is not an appropriate way of pursuing economic growth, but that price stability is a prerequisite for achieving sustainable growth and job creation.
} 
In practice, policy decisions are complicated by the fact that the setting in which they are typically made is dynamic in terms of the interaction between thinking agents over time. Not only do policy makers assess the environment and make decisions they deem best, but the public also acts in its own best interests. Monetary policy models have largely been based on the assumption that decision makers form expectations in a 'rational' way. This calls attention to the strategic nature of the interaction. Through their economic decisions, the private sector and monetary authorities impact on one another's decisions. These ideas have had substantial implications for policy, guided by compelling developments in the theory ${ }^{2}$.

In an evaluation of four monetary regimes, Mishkin (1999) identifies the use of a nominal anchor as a fundamental commonality. He narrowly describes a nominal anchor as 'a constraint on the value of domestic money' and more broadly 'a constraint on discretionary policy' (1999: 1). He concludes that transparency and accountability are essential to this end, regardless of the specific strategy adopted by the country. By maintaining transparency, central banks are allowing themselves to be held accountable and limiting their own discretion.

In conclusion, transparency, accountability, credibility, and commitment to rules-based policies have become central to the implementation of modern monetary policy. When policy makers commit themselves to greater transparency and accountability in a way that is believable, they give their policy credibility. If policy makers' commitment to low inflation is regarded as trustworthy, the markets should believe that inflationary spikes are transitory. The market's inflation expectations of the longer-term future would remain low; therefore, markets would not adjust their decisions in a way that adds upward inflationary pressure. This would allow the monetary authority to use less aggressive adjustments to their instrument in order to maintain price stability, and the cost of tighter monetary policy on output (the sacrifice ratio) would be lower. In this sense there is a strategic reason for coordination between the financial markets and the central bank.

\section{REVIEW OF THE EVIDENCE: TRANSPARENCY AND CREDIBILITY OF SOUTH AFRICAN MONETARY POLICY}

Current discussion surrounding inflation expectations and the degree to which the SARB is effectively managing inflation expectations in South Africa is dominated by analyses of macroeconomic trends, inflation expectation surveys, and 'break-even' rates (the difference between nominal and inflation-indexed bonds of similar maturity) - see Reid

\footnotetext{
2 Theoretical developments of particular relevance are: the Lucas critique (Lucas, 1976), the understanding that policy can be time inconsistent (Kydland and Prescott, 1977), and the definition of monetary policy as a path of policy stances over time (Sargent and Wallace, 1981). For a survey of work on credibility since 1981 see Walsh (2003).
} 
(2009), for a more comprehensive discussion of these. However, none of the above measures directly examines the relationship between the changes in the monetary policy instrument and other market interest rates.

Ballim and Moolman (2005) contribute to the literature by investigating the impact of changes in the repo rate on a range of financial market instruments in order to capture the response of interest rates at different horizons. These include forward rate agreements (FRAs) with maturities of less than a year and government bonds with longer maturities. Using a variety of empirical tests, they find strong correlations (diminishing with longer horizons) between movements in the repo rate and short-term interest rates, and they find that the majority of the market adjustment occurs before the decision is announced, suggesting that markets are anticipating changes in the repo rate.

Aron and Muellbauer (2006) extend the former study by using FRAs with different dimensions to identify the expectations of the markets regarding following policy decisions more clearly. However, their results are similar to those of Ballim and Moolman (2005).

These two studies begin to empirically scrutinise the causal relationship between monetary policy and market interest rates. Aron and Muellbauer (2006) still question the strong policy conclusions drawn by Ballim and Moolman and propose that a comparison of the magnitudes of the responses with those of another country would provide more indication of the room for improvement.

To avoid measurement error, it is also preferable to use the 'surprise' (the difference between the forecasted value and the actual value realised) of the market after the announcement of a monetary policy decision as the independent variable, rather than simply to use the change in the repo rate. The markets may be surprised by the failure of the SARB to adjust the repo rate, or conversely, a change in the policy rate may be entirely anticipated. The surprise component provides a more precise measure of the new information presented to the market, to be considered when pricing instruments. These issues will be addressed by the empirical study in the following section.

\section{THE SENSITIVITY OF INFLATION EXPECTATIONS TO ‘SURPRISES’ IN SOUTH AFRICA}

Recent work in a series of papers beginning with Gürkaynack, Sack and Swanson (2005a), have offered exciting new insights. They investigated the impact of new information (macroeconomic data and monetary policy 'surprises') on short- and long-term interest rates (the term structure of the interest rate). 
Using advances in the literature regarding how to measure the market's expectations of interest rates and inflation in a period far into the future, Gürkaynack, Sack and Swanson (2005a) find that long-term expectations (as captured by the long-term forward inflation compensation rates) in the US are not as well anchored ${ }^{3}$ as one might have expected. Subsequent research found that long-term inflation expectations in the US and in pre1997 UK (before the Bank of England (BoE) gained independence ${ }^{4}$ ) were far more sensitive to surprise information than those of Sweden and post-1997 UK (Gürkaynack, Levin and Swanson, 2006). They interpreted this as evidence that anchoring long-term inflation expectations was enhanced through inflation targeting.

These findings were reinforced through a study by Mauricio Larrain (2005) from the Central Bank of Chile, who examined the effect of monetary policy surprises on the term structure of interest rates in Chile. He found that inflation expectations in Chile (an emerging market) compared favourably with those of the US. The study by Gürkaynack, Sack and Swanson has also been extended to test its applicability to Canada and Chile (Gürkaynack, Levin, Marder and Swanson, 2005). The results bolstered those of the original study, with the forward inflation compensation (difference between the forward rates of nominal and real bonds) of Canada and Chile not showing significant responses to domestic macroeconomic data and monetary policy surprises. An interesting peculiarity of this article is that the Canadian far-ahead interest rates did show a degree of sensitivity to news from the US, although it was still less than the response of the US.

That inflation-targeting central banks are more credible than the Federal Reserve Bank would be an unpersuasive argument. It is more likely that the systematic implementation and communication of monetary policy in the inflation targeting countries reduces the uncertainty experienced by financial markets in these countries. If a central bank were more transparent about its plans for future policy, it would potentially be able to shape market expectations more directly and improve coordination.

In this section, the methodology of Gürkaynack, Sack and Swanson (2005a) is applied in order to more directly evaluate the link between monetary policy and the financial markets in South Africa. It sheds light on the degree to which the international findings of Gürkaynack, Sack and Swanson (2005a) are applicable to South Africa, and investigates how well inflation expectations have been anchored in South Africa over the past five years, relative to countries discussed in other articles above.

\footnotetext{
${ }^{3}$ A nominal anchor should convince the public that the authorities will control inflation in the long run. Therefore, the longer-term inflation expectations of the public should not react strongly to new information.

4 The hypothesis is that an independent $\mathrm{BoE}$ should have more credibility because it reduces the extent to which the government can use monetary policy to pursue other goals and sacrifice the attainment of the BoE's objectives.
} 


\section{a) Data and Methodology}

As with many studies performed in less developed countries, the availability of data, especially in the form required, was a challenge. ${ }^{5}$ Following the model of Gürkaynack, Sack and Swanson (2005a), variables were created to capture the 'surprise' experienced by the markets, following a number of macroeconomic data releases and monetary policy decisions; and the variable 'forward inflation compensation' was created as a measure of the inflation expectations of the markets.

This enables an estimate of the impact of the surprises on the inflation expectations of the market during this period, using the following regression:

$$
\Delta F I C_{t}=\alpha+\beta_{1} C P I X_{t}+\beta_{2} G D P_{t}+\beta_{3} C A_{t}+\beta_{4} P P I_{t}+\beta_{5} R E P O_{t}+\varepsilon_{t}
$$

The change in the forward inflation compensation on day $\mathrm{t}\left(\Delta F I C_{t}\right)$ was regressed on the surprise components of the macroeconomic announcements on the corresponding day t. CPIX, GDP, CA and PPI are the surprise components of the consumer price index (excluding mortgage costs), gross domestic product, current account and producer price index data releases respectively; and REPO is the surprise component of the monetary policy decision regarding the setting of the repo rate. $\varepsilon_{t}$ represents the factors that influence forward inflation compensation other than regressors used.

The data set consists of daily observations of the changes in the inflation compensation on the day of each announcement. Only days on which an announcement was made are included, and usually only one announcement took place each date. So on any particular date, only one non-zero surprise was measured and all the other surprises on that date would be recorded as zero. The regression results can be interpreted as the extent to which inflation compensation responds (on average) to the surprise components of macroeconomic announcements over the sample period (May 2002 - March 2007).

\section{a) i) Macroeconomic surprises}

The 'surprise' component of the macroeconomic data announcements was isolated to reflect the fact that the balance of the movement of the macroeconomic data is not

\footnotetext{
${ }^{5}$ In a footnote, Gürkaynack, Levin and Swanson (2006) identify some of the ways in which data limitations (which tend to be worse in developing countries) have frustrated efforts to apply their methods to other inflation targeting countries.

${ }^{6}$ The sample period was limited May 2002-March 2007 for practical, data collection reasons. The start of the sample was limited by the dates at which the inflation indexed government bonds were introduced, and the reason that the sample period ends in 2007 is that the construction of the dataset that preceded this study began in mid-2007.
} 
'news' to them and will therefore not be responsible for the movements of the interest rates. Abrupt movements of the interest rate shortly after the announcement would reflect the extent to which they misjudged the actual outcome. This is the extent to which the markets have received new information which has not yet been reflected in the pricing. Using the surprise component of the variables also limits the possibility of endogeneity, because the expected feedback from the interest rates to the macroeconomic variables is removed when constructing the surprise variables (Gürkaynack, Levin and Swanson, 2006). To capture the surprise of the markets at the release of macroeconomic data, Gürkaynack, Sack and Swanson (2005) calculated the difference between the actual data released and the median forecast of a panel of professional forecasters, polled shortly before that data release.

$$
\text { surprise }=\text { actual release }- \text { median forecast }
$$

For the purposes of this study of the South African situation, the macroeconomic variables considered were CPIX, PPI, GDP and CA. These were selected due to the availability of survey data and their high degree of relevance to inflation expectations.

With regard to the actual data releases, Van Walbeeck (2006) recently expressed concern regarding the size of the official revisions to South African national accounts data, and the impact of these on econometric studies using this data. He found that the official figures were often adjusted substantially as more accurate information became available to the statistical authorities. The implication for the data set used in this study is that the surprise experienced by the market following a data release may be dispersed over time, as the official figures are revised. On consideration, first-release data was used, because, as Van Walbeeck (2006) pointed out, the first release receives the most attention.

A series of consensus forecasts were required to capture the expectations of the markets regarding the relevant macroeconomic variables. The median of forecasts from the panel of economists was used (rather than the mean) in order to limit the influence of changes in composition of the panel, and to minimise the effect of outliers.

The precise publication dates of the data were necessary to match the forecast and actual data releases accurately, and then to match these surprise components with the movement in the forward inflation compensation on the day of each 'surprise'.

\section{CPIX:}

The first releases of CPIX were collected from consecutive issues of the SARB Quarterly Bulletin (2002 - 2007) by collecting only the last figures, which had not yet been revised, from each issue. Publication dates were provided by Stats SA and were compared with 
media reports, where available (Business Day - various issues, 2002 - 2007), to confirm that there were no discrepancies due to delayed data releases.

To capture the market's expectations of the CPIX, the Reuters 'Econometer'7 was considered first, as it is a comprehensive and reputable survey that has been conducted since October 1999. Unfortunately, although the economists are polled monthly, they forecast for the end of the quarter; therefore, matching the CPIX data releases (released monthly) with the forecast becomes a bit contrived ${ }^{8}$. The Beeld newspaper's 'economist of the year' competition posed the same problem. This increases the potential for measurement error and simultaneity. Alternatively, a series of surveys conducted by Bloomberg (2002 - 2007) ${ }^{9}$ within the week leading up to the data release was used for the forecast of CPIX. This allowed the surprise resulting from each individual release to be captured more accurately.

\section{Figure I:}

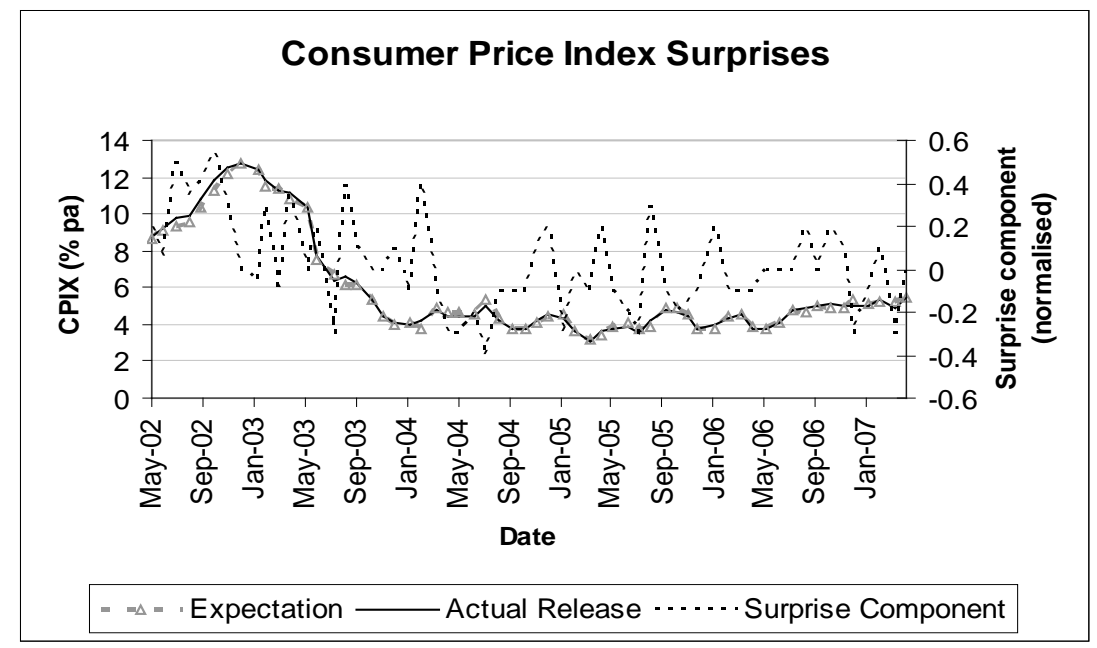

Source: Bloomberg, the SARB Quarterly Bulletins (2002 - 2007), Stats SA (as above).

Surprise component - own calculation.

Figure I shows the actual CPIX series, the forecast CPIX series and the surprise component. The actual and forecast series run relatively closely together, which is confirmed by the dotted line representing the surprise component, which fluctuates gently around zero.

\footnotetext{
${ }^{7}$ Forecasts of a panel of professional economists.

${ }^{8}$ Although Reuters do survey the market's expectations of some data releases for a shorter horizon, only the past two years worth of surveys were available in their archives at any time.

9 Bloomberg conducts surveys for a small range of macroeconomic data releases. A panel of professional economists is surveyed in the week leading up to the data releases.
} 


\section{PPI:}

The PPI is also released monthly. Both the first releases of the actual data and the forecasts (conducted in the week leading up to the data release) were received from Bloomberg. The dates on which the data was published were collected from consecutive, electronic statistical publications (Stats SA, 2002 - 2007).

Figure II:

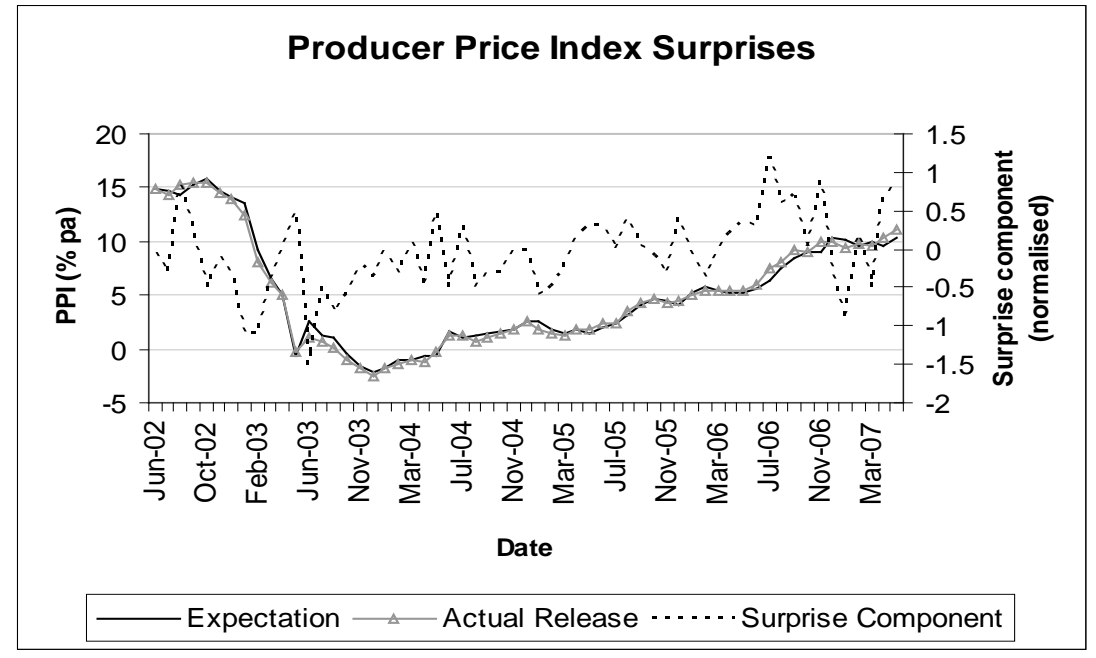

Source: Bloomberg, Stats $S A$ (as above).

Surprise component - own calculation.

GDP:

Publication dates of the quarterly GDP series were collected from consecutive, electronic statistical publications by Stats SA (2002 - 2007). The first releases of the actual data were collected from the SARB Quarterly Bulletins (2002 - 2007). The GDP forecasts were received from Bloomberg. 


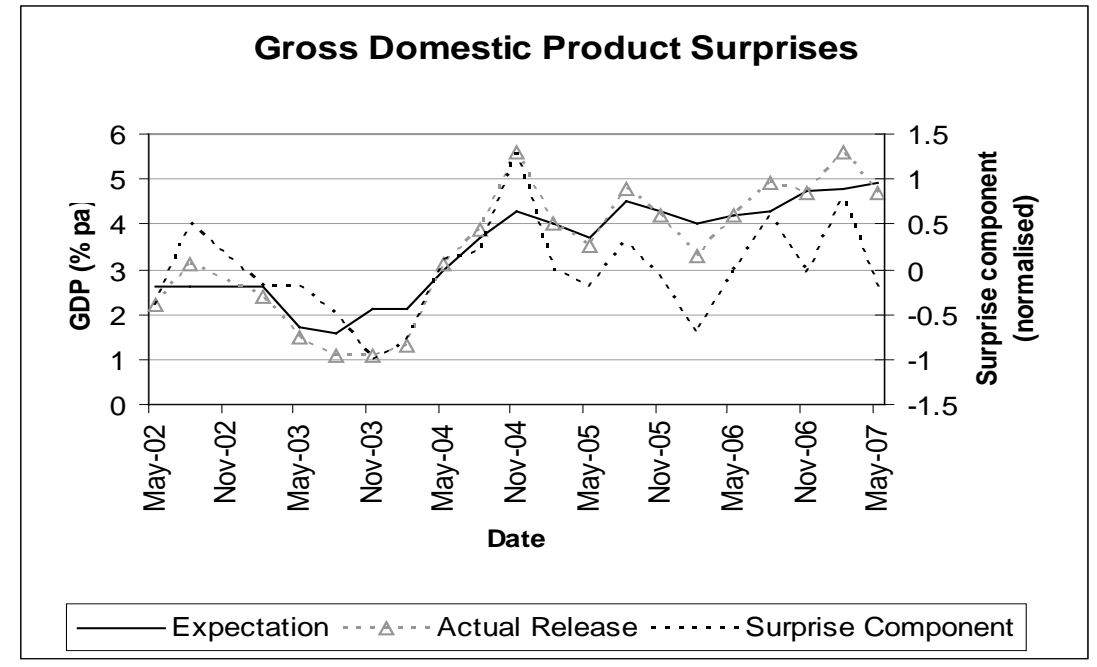

Source: Bloomberg, the SARB Quarterly Bulletins (2002 - 2007), Stats SA (as above).

Surprise component - own calculation.

\section{Current Account:}

The first releases of the actual data were collected from consecutive issues of the SARB Quarterly Bulletin (2002 - 2007). The dates on which the SARB Quarterly Bulletins were released by the Reserve Bank, which would be the first public release of the current account data, was provided by the SARB ${ }^{10}$.

Bloomberg did not provide forecasts of the current account releases the week before the data release. Instead, the Reuters Econometer was used, but this was not as much of a problem as for the CPIX, as the actual current account data is only released once per quarter. As described above, the Reuters panel forecasts their expectation monthly for the end of the quarter; therefore, there are three forecasts for each quarter. The last forecast of the three before the release of the actual current account data (here the panel forecasts for the end of the month) was used in an attempt to capture the market's expectation of the current account balance as close to the data release as possible.

\footnotetext{
10 Gratitude is expressed to Adri Cronjé of the SARB for providing the dates on which the Quarterly Bulletins were distributed.
} 


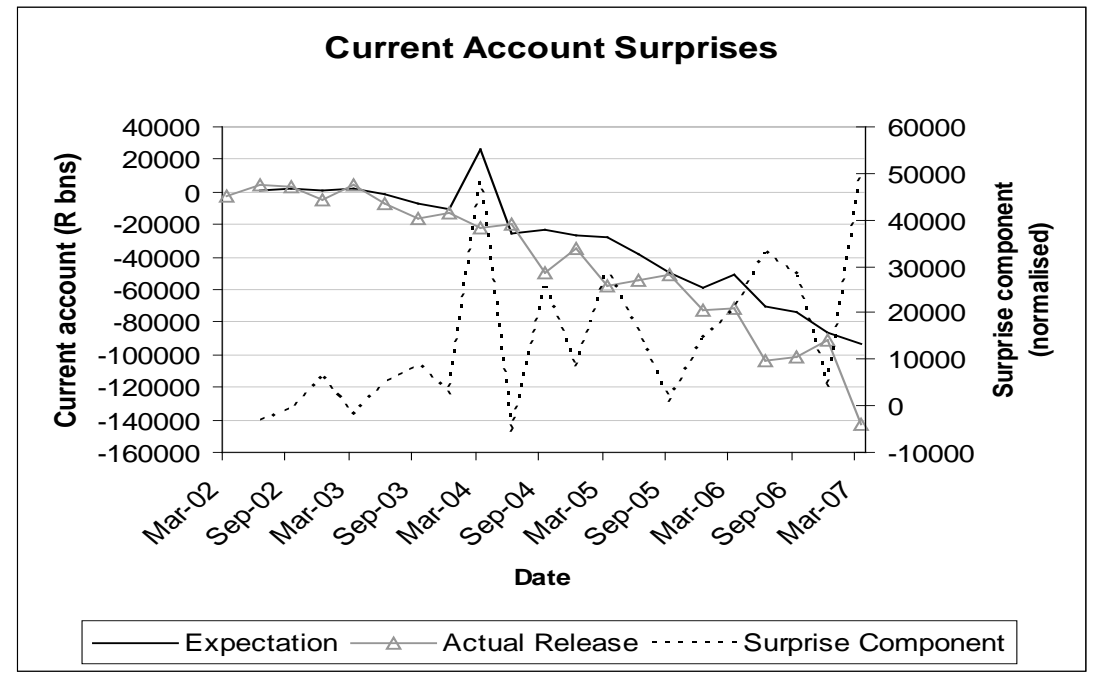

Source: The SARB, the SARB Quarterly Bulletin (various issues, 2002 - 2007), Reuters Econometer.

Surprise component - own calculation.

In order to ensure comparability of the macroeconomic 'surprises' and ease interpretation, the different macroeconomic surprises were normalised, by dividing each series by its standard error (Gürkaynack, Sack and Swanson, 2005a). The coefficient on each macroeconomic surprise in the regression should be interpreted as the variation in the forward inflation compensation caused by a 1 standard deviation of the surprise.

\section{a) ii) Monetary policy surprises}

The surprise component for monetary policy was calculated using market data rather than the surveys, as this is available at a much higher frequency and is of a higher quality. The change in the three-month Bankers Acceptance (BA) Rate (the SARB, 2007) on the day after the monetary policy committee (MPC) makes its statement ${ }^{11}$ was used as a proxy for this surprise component. The MPC announcement is made at $3 \mathrm{pm}$, whereas the BA rate is set by the banks at midday; therefore, the BA rate would only reflect any surprise experienced by the markets the following day.

The monetary policy surprise series was not normalised, and the coefficient on repo is interpretable as the basis point variation in the forward interest rate, due to a basis point variation in the monetary policy surprise variable. Bear in mind that the MPC statement communicates the decision of the monetary policy committee regarding the present changes in the policy instrument, but it may also provide an indication of the possible future policy stance of the committee.

${ }^{11}$ Dates of MPC meetings from MPC statements (2002 - 2007). 
Figure V:

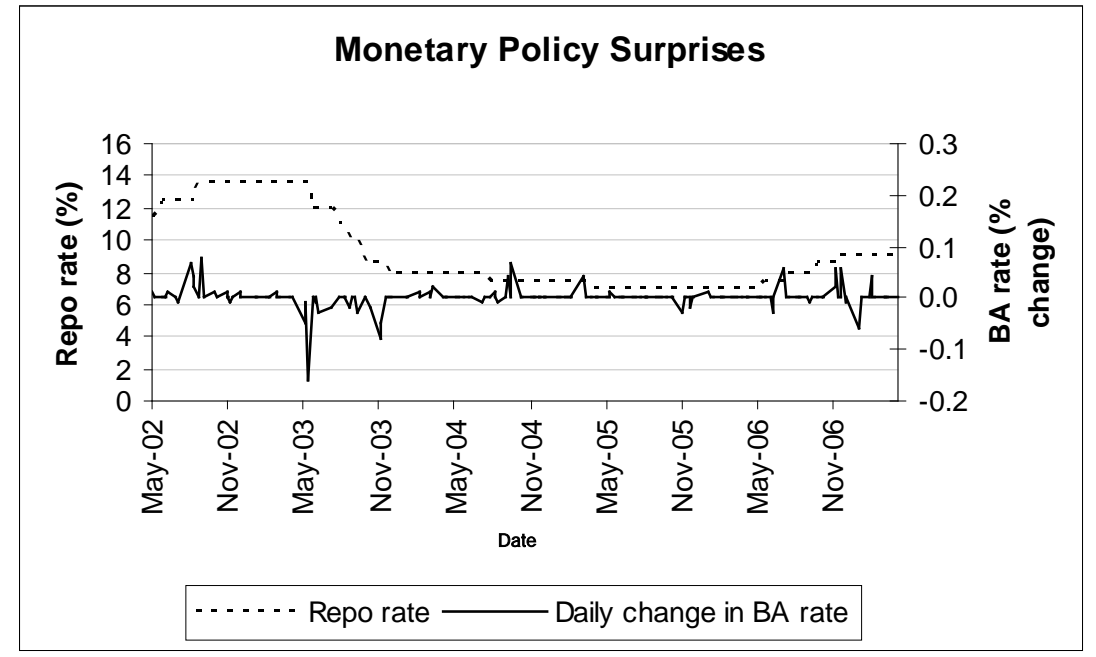

Source: Data from the $S A R B$.

Figure $\mathrm{V}$ represents the surprise of the markets following a monetary policy decision (solid line), and the path of the actual monetary policy decisions (dashed line). Sharp movements of the solid line represent the times when the market was surprised by monetary policy decisions. During the second half of 2002 and the first half of 2003 when the repo rate was being adjusted frequently to manage the peak in inflation at the time, the market was more likely to misjudge the movements of the SARB. The two instances referred to earlier (April 2005 and June 2006), when the market strongly criticised the SARB for its lack of predictability, are also reflected in the figure.

\section{a) iii) Measurement of inflation expectations}

Gürkaynack, Sack and Swanson (2005a) isolated the inflation expectations of the market by finding the forward inflation compensation ${ }^{12}$, which is the difference between nominal and real forward interest rates. Forward rate agreements, which are traded in the markets, are only available with horizons of up to one year, whereas longer horizons are more appropriate for this study. However, yield, spot and forward rate curves all present the same underlying term structure information in different ways, so nominal and real implied forward rates could be calculated using bond data (Coleman, 1998). Implied forward rates and inflation compensation calculated for South Africa in a previous paper (Reid, 2009) will be used here as a measure of inflation expectations for the period May 2002 March 2007.

\footnotetext{
12 Inflation compensation includes both the market's expectations of future inflation and the inflation risk premium (the uncertainty associated with inflation at this horizon).
} 
According to the Fisher equation, the nominal interest rate can be decomposed into the real interest rate and inflation expectations:

$i_{t}=r_{t}+\pi_{t+1}^{e}$

where $i_{t}=$ nominal interest rate

$$
\begin{aligned}
& r_{t}=\text { real interest rate } \\
& \pi_{t+1}^{e}=\text { inflation expectations }
\end{aligned}
$$

Svensson (1994) proposed the use of forward interest rates for analysing monetary policy, because a forward interest rate is related to an ordinary yield curve in the same manner as average and marginal cost curves are related. Forward rates at a long-term horizon, show the expected short-term interest rates at that horizon. Relying on the Fisher equation, forward inflation compensation at a particular horizon can be presented as the difference between nominal and real forward rates at that horizon:

Fwd inflation compensation $=$ nom fwd rate - real fwd rate

Inflation compensation is, however, an imprecise measure of inflation expectations, because according to the asset pricing model, a term for the risk premium should be added to the Fisher equation (the nominal interest rate should be decomposed into the real interest rate, expected inflation, and the risk premium).

Both Sack (2002) and Gürkaynack, Levin and Swanson (2006) acknowledge that inflation compensation does not capture expected inflation precisely, and they do not lightly disregard the influence of risk premia, but they insist that these factors do not discredit their results. If the variations in the risk premia over time are at lower frequencies than the daily variations in forward inflation compensation (the dependent variable), the risk premia should not have much influence on the coefficient estimates (Gürkaynack, Levin and Swanson, 2006). Even if the premia decrease substantially over time, their movement in one day will be very small.

\section{b) Regression results}

The original studies (Gürkaynack, Sack and Swanson, 2005a, and Gürkaynack, Levin and Swanson, 2006) use dynamic stochastic general equilibrium (DSGE) models as benchmarks, from which they emphasise two important observations. Firstly, in agreement with a variety of macroeconomic models, the DSGE models show that within five (or at least ten) years, the short-term interest rates return to their steady state. 
Secondly, if the short-term interest rate is approximately the average of all short-term interest rates over the life of the bond, then it follows that this long-term interest rate will move when economic news is released, as the shorter-term interest rates will respond. However, the forward rate at a long horizon (between years four and five, or nine and ten in this case) should not respond to economic news in the present time period if inflation expectations are well anchored and transitory responses to shocks disappear before the long-term horizon is reached ${ }^{13}$. If the forward interest rates at the long horizons do respond, it suggests that there is pass-through of the economic shock to the inflation expectations.

\section{b) i) Results of this study}

Over the sample period of this study, South Africa was an inflation targeter, and the oneyear forward inflation compensations - ending in five and ten year's time - are expected to be well anchored. Using the variables created above, this was investigated by regressing the nominal spot rate and forward inflation compensation rates on the surprise variables, using the method of ordinary least squares adopted by Gürkaynack, Sack and Swanson. ${ }^{14}$

\footnotetext{
13 Based on the benchmark DSGE models, the system should have reached a steady state by five (or at least ten) year's time, and therefore, the transitory responses should have died out (Gürkaynack, Levin and Swanson, 2006).

14 As mentioned earlier, the possibility of endogeneity due to the impact of interest rates on the macro economy is limited by using the surprise component of the macroeconomic data releases. In addition, using auxillary regressions and Klein's rule of thumb, the level of multicollinearity was judged not to be a serious concern. The regressions do suffer from positive autocorrelation, so Newey-West standard errors are reported in Table I.
} 
Table I: Impact of Macroeconomic Surprises on Spot and Forward Inflation Compensation Rates

\begin{tabular}{|c|c|c|c|c|}
\hline & $\begin{array}{c}1 \text {-year nominal spot } \\
\text { rate }\end{array}$ & $\begin{array}{l}\text { 1-year forward } \\
\text { inflation } \\
\text { compensation } \\
\text { ending in } 1 \text { year }\end{array}$ & $\begin{array}{c}\text { 1-year forward } \\
\text { inflation } \\
\text { compensation } \\
\text { ending in } 5 \text { years }\end{array}$ & $\begin{array}{c}\text { 1-year forward } \\
\text { inflation } \\
\text { compensation } \\
\text { ending in } 10 \text { years }\end{array}$ \\
\hline CPIX surprise & $\begin{array}{l}0.885^{* * *} \\
(0.250)\end{array}$ & $\begin{array}{l}0.746^{* * *} \\
(0.228)\end{array}$ & $\begin{array}{l}0.147 \\
(0.180)\end{array}$ & $\begin{array}{l}0.029 \\
(0.102)\end{array}$ \\
\hline PPI surprise & $\begin{array}{l}-0.289 \\
(0.250)\end{array}$ & $\begin{array}{l}-0.147 \\
(0.238)\end{array}$ & $\begin{array}{c}0.132 \\
(0.098)\end{array}$ & $\begin{array}{c}0.064 \\
(0.067)\end{array}$ \\
\hline GDP surprise & $\begin{array}{r}0.185 \\
(0.485)\end{array}$ & $\begin{array}{c}0.330 \\
(0.500)\end{array}$ & $\begin{array}{l}-0.014 \\
(0.216)\end{array}$ & $\begin{array}{l}0.028 \\
(0.115)\end{array}$ \\
\hline Current account surprise & $\begin{array}{l}-0.516^{* *} \\
(0.218)\end{array}$ & $\begin{array}{l}-0.434^{* *} \\
(0.168)\end{array}$ & $\begin{array}{l}-0.228 \\
(0.151)\end{array}$ & $\begin{array}{l}-0.031 \\
(0.088)\end{array}$ \\
\hline REPO rate Surprise & $\begin{array}{r}1.428 \\
(1,081)\end{array}$ & $\begin{array}{l}1.640^{*} \\
(0.952)\end{array}$ & $\begin{array}{l}1.305^{*} \\
(0.698)\end{array}$ & $\begin{array}{l}0.331 \\
(0.349)\end{array}$ \\
\hline Number of observations & 168 & 168 & 168 & 168 \\
\hline $\mathrm{R} 2$ & 0.092 & 0.088 & 0.039 & 0.007 \\
\hline Prob (F-statistic) & $0.007^{* * *}$ & $0.010^{* * *}$ & 0.266 & 0.948 \\
\hline
\end{tabular}

Note: The sample period for the study is May 2002 to March 2007. The numbers in the columns are the coefficient values and those in brackets are the corresponding standard errors (Newey-West statndard errors were used). The coefficient on each of the macroeconomic surprises should be interpreted as the variation in the forward inflation compensation caused by a 1 standard deviation of the surprise. The coefficient on REPO is interpretable as the basis point variation in the forward interest rate due to the variation in the monetary policy surprise variable, measured in basis points. *** indicates statistical significance at the 1\% level, ** at the 5\% level and * at the 10\% level. The probably value of the F statistic represents the probability that all the coefficients are jointly equal to zero.

The surprise components of the macroeconomic data and monetary policy announcements are listed vertically, in rows, in Table I above. The regression results reporting the sensitivity of the one-year spot to these surprise components are presented in the first column, and the sensitivity of the one-year forward inflation compensation ending in one year's time is presented in column two of Table I. Column one has two highly significant coefficients and the $\mathrm{R}^{2}$ of $9.2 \%$ suggests that these variables do explain a portion $(9.2 \%)$ of the variation in the nominal rate. The probability of the $\mathrm{F}$ statistic $(0.7 \%)$ indicates that the hypothesis that all coefficients are jointly equal to zero can be rejected even at the $1 \%$ level of significance. Similarly, column two has three significant coefficients, an $\mathrm{R}^{2}$ of $8.8 \%$ and the probability of the $\mathrm{F}$ statistic of $1 \%$. Although the $\mathrm{R}^{2}$ of these two regressions shows that a substantial amount of the variation in the nominal rate and the inflation compensation ending in one year's time is not explained by the surprise variables included in the regressions, the significant variables and highly significant $\mathrm{F}$ statistic show that the regression variables do contain some information relevant for the movement of short-term interest rates. These statistics are also comparable to the international results in the original studies, which are discussed in the following section. The question is whether this information passes through to long-term inflation expectations (whether the markets believe the shocks are transitory). 
Columns three and four, analysing the sensitivity of the one-year forward inflation compensation ending in five and ten year's time to the surprise components, attempts to answer this question. The coefficients get progressively less significant, while the $\mathrm{R}^{2}$ decreases and the F-statistic increases. The results of inflation compensation at the tenyear horizon are especially strong. All the coefficients are insignificant, the $\mathrm{R}^{2}$ suggests that only $0.7 \%$ of the variation in the inflation compensation can be explained by the surprises, and the probability of the F statistic (0.948) suggests that the hypothesis that all coefficients are jointly equal to zero cannot be rejected. The crucial point is how the statistics have changed. For example, the $\mathrm{R}^{2}$ of $0.7 \%$ at the ten-year horizon is less than one thirteenth $(7.6 \%)$ of the size of the $\mathrm{R}^{2}$ of the one-year inflation compensation ending in ten year's time.

It is also interesting to contrast the persistence of the effects of the announcements in South Africa with those of the United States, as described by Gürkaynack, Sack and Swanson (2005a). In Figure VI the regression coefficients for South Africa (with 95\% confidence intervals) are plotted to depict the impact of each surprise variable on one year forward rates ending in 1 to 10 years time. The coefficients of each of the variables in the present study reach around zero within a ten year period, with the coefficient for GDP reaching zero as quickly as 3 years. In contrast, the results in Gürkaynack, Sack and Swanson (2005a) show that the effects for many of the variables in the United States take up to 15 years to reach zero.

Figure VI: Sensitivity of Forward Rates to Macroeconomic Surprises
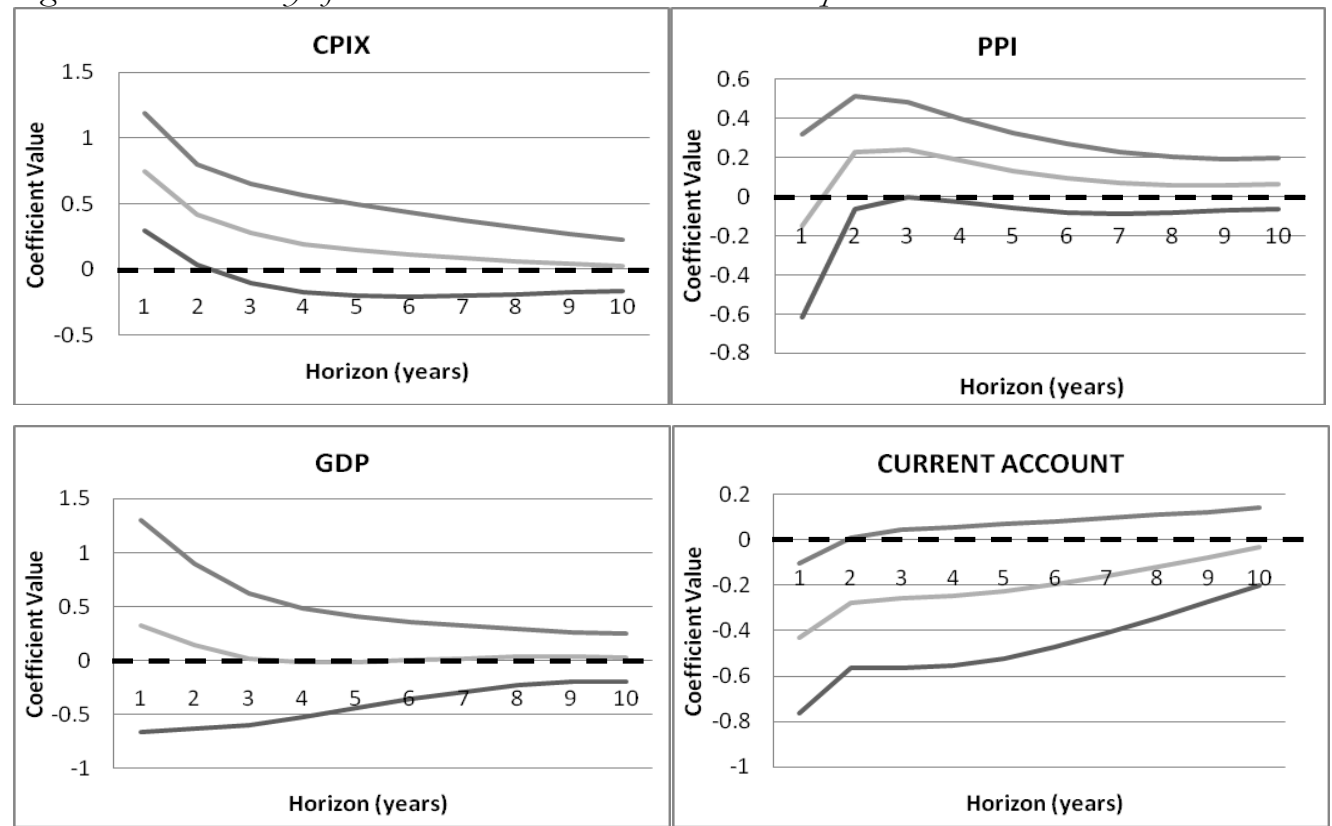


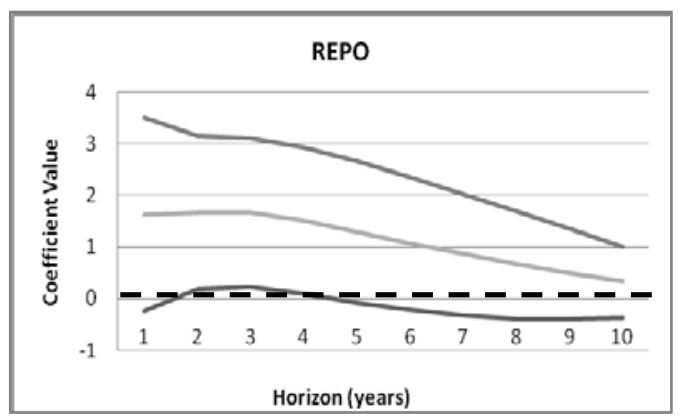

Source: Own calculations ${ }^{15}$

\section{b) ii) Comparison with international findings}

The results for South Africa in the previous section are in line with those of Gürkaynack, Levin and Swanson (2006) for Sweden and the UK (after the BoE was granted independence), and those of Gürkaynack, Levin, Marder and Swanson (2005) for Chile ${ }^{16}$, which are summarised in Table II. Notice that all these countries adopt the inflation targeting framework.

Comparing the results for the nominal spot rate and the one-year inflation compensation ending in ten year's time, the coefficients for the surprise variables in Sweden and the UK (post- central bank independence) become substantially less significant. The $\mathrm{R}^{2}$ decreased from $7 \%$ to $1 \%$ in Sweden and from $24 \%$ to $3 \%$ in the UK after BoE independence. The Chilean example as an emerging market inflation targeter reinforces these results.

It is illuminating to compare the above with the results for the US and the UK (precentral bank independence). The decrease in the $\mathrm{R}^{2}$ for the US is proportionately much smaller and, although the significance of the coefficients decrease, five of the eleven

15 Gürkaynack, Sack and Swanson (2005a) emphasise that the 95\% confidence bands do not get wider with longer horizons as the regressions are not predicting the level of the interest rates that will be realised at those horizons, but rather revisions to the expectations of those interest rates. 
Table II: A Summary of Some of the International Results

\begin{tabular}{|c|c|c|}
\hline & 1-year spot rate & $\begin{array}{l}\text { 1-year forward inflation } \\
\text { compensation ending in } 10 \text { year }\end{array}$ \\
\hline \multicolumn{3}{|c|}{ US (Gürkaynack, Levin and Swanson, 2006 ) } \\
\hline $\begin{array}{l}\text { No. of coefficients significant at } 1 \% \text { level } \\
\text { of significance }\end{array}$ & 8 of the 11 variables & 3 of the 11 variables \\
\hline $\begin{array}{l}\text { No. of coefficients significant at } 5 \% \text { level } \\
\text { of significance }\end{array}$ & 2 of the 11 variables & 2 of the 11 variables \\
\hline $\mathrm{R}^{2}$ & 0.16 & 0.05 \\
\hline Prob (F-statistic) & $0.000^{* * *}$ & $0.000^{* * *}$ \\
\hline \multicolumn{3}{|c|}{ UK (before central bank independence) (Gürkaynack, Levin and Swanson, 2006 ) } \\
\hline $\begin{array}{l}\text { No. of coefficients significant at } 1 \% \text { level } \\
\text { of significance }\end{array}$ & 5 of the 7 variables & 2 of the 7 variables \\
\hline $\begin{array}{l}\text { No. of coefficients significant at } 5 \% \text { level } \\
\text { of significance }\end{array}$ & 0 of the 7 variables & 2 of the 7 variables \\
\hline $\mathrm{R}^{2}$ & 0.35 & 0.21 \\
\hline Prob (F-statistic) & $0.000^{* * *}$ & $0.000^{* * *}$ \\
\hline \multicolumn{3}{|c|}{ UK (after central bank independence 1998 - 2005) ( Gürkaynack, Levin and Swanson, 2006 ) } \\
\hline $\begin{array}{l}\text { No. of coefficients significant at } 1 \% \text { level } \\
\text { of significance }\end{array}$ & 6 of the 7 variables & 1 of the 7 variables \\
\hline $\begin{array}{l}\text { No. of coefficients significant at } 5 \% \text { level } \\
\text { of significance }\end{array}$ & 0 of the 7 variables & 0 of the 7 variables \\
\hline $\mathrm{R}^{2}$ & 0.24 & 0.03 \\
\hline Prob (F-statistic) & $0.000^{* * *}$ & 0.051 \\
\hline \multicolumn{3}{|c|}{ Sweden (Gürkaynack, Levin and Swanson, 2006) } \\
\hline $\begin{array}{l}\text { No. of coefficients significant at } 1 \% \text { level } \\
\text { of significance }\end{array}$ & 2 of the 8 variables & 0 of the 8 variables \\
\hline $\begin{array}{l}\text { No. of coefficients significant at } 5 \% \text { level } \\
\text { of significance }\end{array}$ & 1 of the 8 variables & 0 of the 8 variables \\
\hline$\overline{\mathrm{R}^{2}}$ & 0.07 & 0.01 \\
\hline Prob (F-statistic) & $0.000^{* * *}$ & 0.420 \\
\hline \multicolumn{3}{|c|}{ Chile (Gürkaynack, Levin, Marder and Swanson, 2005) } \\
\hline $\begin{array}{l}\text { No. of coefficients significant at } 1 \% \text { level } \\
\text { of significance }\end{array}$ & 1 of the 4 variables & 0 of the 4 variables \\
\hline $\begin{array}{l}\text { No. of coefficients significant at } 5 \% \text { level } \\
\text { of significance }\end{array}$ & 0 of the 4 variables & 0 of the 4 variables \\
\hline$\overline{\mathrm{R}^{2}}$ & 0.16 & 0.02 \\
\hline Prob (F-statistic) & $0.005^{* * *}$ & 0.733 \\
\hline
\end{tabular}

Note: *** indicates statistical significance at the $1 \%$ level, ** at the $5 \%$ level and * at the $10 \%$ level.

coefficients are still significant at the ten-year horizon. The results are even stronger for the UK before central bank independence, with the $\mathrm{R}^{2}$ only decreasing from $35 \%$ to $21 \%$ 
and clearly reflecting a strong pass-through from economic shock to inflation expectations at the long horizon. Gürkaynack, Levin and Swanson (2006) suggest that these results support the contention that the inflation targeting framework of Sweden and the UK, after central bank independence, result in a better anchoring of inflation expectations than the US (as a non inflation targeter) and the UK before central bank independence.

\section{A MATURING REGIME}

The results in this study are compatible with the findings of Mitchell-Innes, Aziakpono and Faure (2007), who claim that South Africa's inflation targeting regime is maturing. They tested for short run and long run Fisher effects in South Africa in the period $2000-$ 2005, in order to determine the extent to which the Fisher hypothesis held (i.e. that inflation expectations were constant and therefore monetary policy was able to influence the real interest rate over the period). They found that the short run Fisher hypothesis did not hold, which they proposed was due to the way the transmission mechanism works under inflation targeting. More importantly, they found that although expected inflation and long run nominal interest rates moved in the same direction, the relationship was only 0,28 . They concluded that this favourably supported the level of credibility of the inflation targeting regime as inflation expectations were not moving one to one with the nominal interest rate, and monetary policy was impacting on the real interest rate.

However, despite the comparative success of the South African inflation targeting regime proposed by these studies, it seems appropriate to stress that credibility should not be taken for granted. Lack of coordination between policy makers and the market on various occasions, suggests that there may be room for improvement in communication of the SARB. Despite warnings of a possible rate changes by the Governor of the SARB, the markets were generally surprised by the April 2005 reduction, and June 2006 rise in the interest rate. Data available to the market and communication from the SARB had not convinced the market that the threat was credible (Joffe, 2006), and analysts questioned the reasons given by the central bank for the interest rate decisions of 2005 and 2006.

As concluded earlier, transparency, accountability, credibility, and commitment to rulesbased policies have become central to the implementation of modern monetary policy. These characteristics encourage coordination between the financial markets and the $\mathrm{SARB}$, in the sense that the financial markets believe the SARB to be credible and therefore adjust their inflation expectations as the SARB wishes them to. This does not suggest any duress, but rather that the SARB and the financial markets, as players in a strategic game, have decided that it is in each of their own best interests to cooperate (Reid, 2008). 


\section{CONCLUSION}

It is important to realise that, although some of the most successful and influential central banks have chosen not to adopt inflation targeting, their execution of monetary policy is converging with that of the inflation targeting central banks (King, 2004). Both groups recognise the strategic nature of monetary policy and use communication and transparency extensively in order to influence expectations and increase the effectiveness of monetary policy. The methodology of Gürkaynack, Sack and Swanson (2005) was applied to South African data in this paper and the results were encouraging. The sensitivity of South African inflation expectations for the period under review is comparable with inflation targeting countries analysed in international studies, suggesting that inflation targeting is offering a useful framework for monetary authorities in South Africa to communicate with the public and thereby anchor inflation expectations. However, credibility building is not a once-off exercise. The SARB should continually strive to promote coordination with the financial markets through transparent and predictable monetary policy.

\section{REFERENCES}

ARON, J and MEUlLbAUER, J. (2006). Review of Monetary Policy in South Africa since 1994. Revised Version of a paper prepared for a joint CSAE-Stellenbosch University conference: South African Economic Policy Under Democracy: a 10 Year Review, 27/28 October 2005.

BALLIM, G, and MOOLMAN, E. (2005). Testing the potency of transparency of the South African Reserve Bank's inflation targeting policy. Hardcover, Standard Bank.

BLOOMBERG. (2007). Macroeconomic Consensus Forecasts, received by email.

BUSINESS DAY. (2002-2007). Various issues.

COLEMAN, T.S. (1998). Fitting Forward Rates to Market Data. http://ssrn.com/abstract=994870.

FRIEDMAN, M. (1968). The Role of Monetary Policy. American Economic Review, 58: 1-17.

GÜRKAYNACK, R, SACK, B, and SWANSON, E. (2005a). The Sensitivity of Long-Term Interest Rates to Economic News: Evidence and Implications for Macroeconomic Models. American Economic Review, 95(1): 425-436.

GÜRKAYNACK, R, LEVIN, A, MARDER, A, and SWANSON, E. (2005). Inflation Targeting and the Anchoring of Inflation Expectations in the Western Hemisphere. Prepared for the Bank of Chile Conference in October 2005 on Inflation Targeting.

GÜRKAYNACK, R, LEVIN, A, and SWANSON, E. (2006). Does Inflation Targeting Anchor Long-Run Inflation Expectation? Evidence Form Long-Run Bond Yields in the U.S, U.K., and Sweden. Federal Reserve Bank of San Francisco Working Paper Series, working paper 2006-09.

JOFFE, H. (2006). Bank must get message right on next interest rate movement. Business Day, 18 July 2006.

KING, M. (2004). Comments on 'Risk and Uncertainty in Monetary Policy' by Alan Greenspan, AEA Annual Conference.

KYDLAND, F and PRESCOTT, E. (1977). Rules Rather than Discretion: The Inconsistency of Optimal Plans. Journal of Political Economy, 85, no 3.

LARRAIN, M. (2005). Monetary Policy and Long-Term Interest Rates in Chile. Central Bank of Chile, working paper No. 335.

LUCAS, R. (1976). Econometric policy evaluation: A critique. The Phillips curve and labour markets. K. Brunner and A.H. Meltzer. Amsterdam, North Holland.

MISHKIN, F.S. (1999). International Experiences with Different Monetary Policy Regimes. National Bureau of Economic Research, working paper No. 7044.

MITCHELL-INNES, H.A., AZIAKPONO, M.J. and FAURE, A.P. 2007. Inflation Targeting and the Fisher Effect in South Africa: An Empirical Investigation. South African Journal of Economics, 75(4): 693-707.

REID, M. B. (2008). Communication in the Strategic Game of Monetary Policy: Publication of an Interest Rate Forecast. Unpublished Master's Thesis. Stellenbosch University, March 2008.

REID, M. B. (2009). Isolating a Measure of Inflation Expectations of the South African Financial Market Using Forward Interest Rates. Economic Research Southern Africa, working paper No. 127, May 2009.

REUTERS. (2006). Econometer, received by e-mail.

SACK, B. (2002). A Monetary Policy Rule Based on Nominal and Inflation-Indexed Treasury Yields. Board of Governors of the Federal Reserve System (US): Finance and Economics Discussion Papers. 
SARGENT, T and WALLACE, N. (1981). Some Unpleasant Monetarist Arithmetic. Federal Reserve Bank of Minneapolis Quarterly Review, 5: 1-17.

SOUTH AFRICAN RESERVE BANK. (2002). The Objectives and Importance of Inflation Targeting. Advertorial published by the SA Reserve Bank in Business Day newspaper, 13 November 2002.

SOUTH AFRICAN RESERVE BANK. (2002 - 2007). Statements of the Monetary Policy Committee.

SOUTH AFRICAN RESERVE BANK. (2001 - 2007). South African Reserve Bank Quarterly Bulletin, various issues.

SOUTH AFRICAN RESERVE BANK. (2007). Statistical and Economic Information. http://www.reservebank.co.za

STATSSA. (2002-2007). Statistical Publications. http://www.statssa.gov.za/publications/findpublication.asp.

SVENSSON, L.E.O. (1994). Estimating and Interpreting Forward Interest Rates: Sweden 1992 - 1994. National Bureau of Economic Research, working paper No. 4871.

VAN WALBEECK, C. (2006). Official revisions to South African national accounts data: Magnitudes and implications. South African Journal of Economics, December 2006: 745 - 765.

WALSH, C. E. (2003). Monetary Theory and Policy. Second Edition. Cambridge: MIT Press. 